\title{
LA REGIÓN METROPOLITANA BOLIVIANA DE LA PAZ-EL ALTO
}

\section{Alfonso David Barrientos Zapata}

Docente emérito de la Universidad Mayor de San Andrés en Taller de Proyectos y la asignatura Urbanismo y Territorio II en la Carrera de Arquitectura. Licenciado en Arquitectura en 1981 de la UMSA; cursó la Maestría en Ciencias del Desarrollo, Mención Planificación del Desarrollo en el CIDES-UMSA. Entre 1998 y 2003 ocupó cargos de dirección en la UMSA; entre 2005 y 2010 fue concejal electo por el municipio de La Paz.

ISNN 1666-6I86. Volumen I3 No 13 (Octubre 20I2) pp. 193-2I6 - Recibido: 09-05-12.Aprobado: 22-08-I2. 


\section{Resumen}

El artículo describe, a juicio del autor, las características principales de las ciudades de La Paz y El Alto, ubicadas al este de Bolivia, que junto con Cochabamba y Santa Cruz constituyen las tres metrópolis del país. Destaca que, en el marco de lo establecido por la Constitución Política del Estado, debe ser considerada Región Metropolitana. Señala que a diferencia de los procesos clásicos de constitución de metrópolis, La Paz-El Alto son el resultado de una división político-administrativa producto de la priorización de intereses políticos, desatención institucional y marginamientos socioculturales. Expresa los procesos de transformación espacial que se dan en la Región Metropolitana y los escenarios y tendencias resultado de su potencial.

Palabras clave

Metrópolis; transformaciones urbanas; ciudades de La Paz y El Alto; Bolivia.

\section{Abstract}

This publication describes the principal characteristics of the conurbation of the cities of La Paz and El Alto located in the East of Bolivia which together with Cochabamba and Santa Cruz constitute the three metropolitan "cities" of the country. It points out that based on the Political Constitution of Bolivia they should be considered Metropolitan Regions. Also, it states that unlike the classical processes of metropolitan formation, the La Paz-El Alto conurbation is the result of a political-territorial division caused by the prioritization of political interests, lack of institutional concerns and socio-cultural marginalization. Concentrating on the La Paz-El Alto conurbation it expresses the spatial transformation processes that occur in what should be defined as a metropolitan region and the scenarios and tendencies that are the result of its potentials.

Keywords

Metropolitan; Urban Transformations; El Alto and La Paz cities; Bolivia. 


\section{LAS REGIONES METROPOLITANAS DEL ESTADO PLURINACIONAL DE BOLIVIA}

En Bolivia aún no es común utilizar la expresión Región Metropolitana para referirse a la concentración poblacional que normalmente con el transcurso del tiempo ha ido acortando las distancias que separaban a las capitales de departamento de las ciudades contiguas, borrando los límites funcionales y morfológicos que hasta antes de la unión estaban perfectamente demarcados.

No obstante que el artículo 280 de la Constitución Política del Estado (Constitución Política del Estado Plurinacional de Bolivia, 2009), vigente desde el 7 de febrero de 2009 , menciona que “... En las conurbaciones mayores a 500.000 habitantes, podrán conformarse regiones metropolitanas”, la poca importancia que se le presta al ámbito territorial en la transformación estatal hace que el empleo de este término vinculado con la Organización Territorial del Estado sea prácticamente desconocido, por tanto aún no se inició el debate que puede conducir a optimizar la organización territorial del nuevo estado.

En el ámbito académico ha sido más usada la expresión área metropolitana; sin embargo, y a pesar de varios intentos de definir su alcance, utilidad, aplicación y componentes metropolitanos, no existe un acuerdo en la identificación de las ciudades que la componen.

Este panorama, lejos de ser desalentador, debe ser estimulante para consolidar un debate que sugiera alternativas de respuesta a los problemas cada vez más acuciantes de los procesos de desplazamiento humano y su concentración en el ámbito denominado urbano. Las proyecciones demográficas demuestran una tendencia inexorable de concentración poblacional en las ciudades, las mismas que históricamente han expresado las características de desequilibrio y desarticulación territorial propias del modo de producción capitalista; desequilibrio y desarticulación que, en el caso boliviano, se presentan por lo menos en dos escalas, la relacionada con la comparación con países vecinos y la que corresponde a la comparación de las ciudades con el interior del país.

De acuerdo con información ya conocida públicamente por organizaciones internacionales (Population Reference Bureau, 2012), y que seguramente se confirmará con la realización, a fines del presente año, del Censo Nacional de Población y Vivienda, Bolivia ya ha superado la barrera de los 10 millones de habitantes. También se afirma que cerca del 70 $\%$ de la población (BANCO Mundial, 2012) está concentrada en el ámbito urbano; pero, de estas referencias globales es necesario precisar que de las nueve capitales de departamento, 
solo en tres ciudades - La Paz, Cercado de Cochabamba y Santa Cruz- se concentra la mayor cantidad de población boliviana; por tanto estas tres y la ciudad de El Alto, contigua a La Paz, pueden constituirse en regiones metropolitanas con la aplicación del artículo 280 de la Constitución Política del Estado, ya que superaron los 500.000 habitantes. De esta manera, se ratifica que la estructura territorial boliviana de 1,8 millones de kilómetros cuadrados es desarticulada y desequilibrada.

Sin duda que producto de condiciones históricas, culturales y físico-naturales existen particularidades y diferencias en estas tres regiones metropolitanas, pero para el desarrollo del presente artículo que se refiere a la región metropolitana de La Paz y El Alto hago énfasis en su origen y dejo a consideración los argumentos en la siguiente parte.

\section{CARACTERÍSTICAS DE LA REGIÓN METROPOLITANA DE LA PAZ Y EL ALTO}

A diferencia de las regiones metropolitanas de Cochabamba y Santa Cruz, que representan el crecimiento de la ciudad principal hasta confundirse con las ciudades y municipios vecinos, La Paz y El Alto siempre formaron una continuidad territorial. Ya en tiempos precoloniales las poblaciones originarias, con su lógica de control vertical del espacio, además de transitar por la actual jurisdicción administrativa de ambas ciudades extendían su control por extensiones mayores que las que ahora ocupa esta región. Los conquistadores españoles en 1548 - para extender su dominio y como parte de su estrategia de control de recursos y territorio - fundaron la ciudad de La Paz en el altiplano, en el lugar que ahora es el municipio de Laja, pero anoticiados del control territorial de los pueblos existentes realizaron una segunda y definitiva fundación en el valle del río Choqueyapu, actualmente municipio de La Paz. Los cronistas de la época señalan como razones para el traslado:

* la buena disponibilidad de agua;

* la ocupación previa de asentamientos;

* la conexión al norte y este con los valles de yungas productores de coca en dirección al actual Amazonas;

* la conexión hacia el oeste con el altiplano, tránsito obligado al Perú con conexión al actual Océano Pacífico y con las minas ubicadas al sur.

Como toda ciudad colonial, su crecimiento estuvo condicionado por la ubicación de la plaza mayor. Las referencias estadísticas señalan que a fines del siglo XVIII la población alcanzaba a 25.000 habitantes, con un porcentaje de población originaria cercano al $50 \%$. 
Después de la fundación de Bolivia, el 6 de agosto de 1825, la población se incrementa, y a fines del siglo XIX alcanza una cifra aproximada de 60.000 habitantes. Para esta época la proporción de población originaria se incrementa a $90 \%$ (GoBIERNo MUNICIPAL DE LA PAZ, 2006).

A principios del siglo XX, luego de la denominada Revolución Federal, la ciudad de La Paz incrementa y fortalece su hegemonía poblacional y de ocupación territorial frente al resto de Bolivia al asumir condición de sede de gobierno. La oligarquía minera y terrateniente de la época se asienta en La Paz y aprovecha el altiplano para la instalación de las infraestructuras más importantes vinculadas con sus intereses; el territorio ocupado actualmente por las ciudades de El Alto y Viacha se constituye en el tramo ferroviario más importante que conecta a La Paz con las ciudades de Oruro, Potosí y además con el Océano Pacífico.

En el año 1923 se construyen el aeropuerto internacional, que para ese entonces era el más importante del país, y también las primeras instalaciones de Yacimientos Petrolíferos Fiscales de Bolivia, infraestructuras que impulsan la concentración de tierras por familias latifundistas, que con posterioridad a la Revolución de 1952 se verán obligadas a cederlas y darán lugar a la formación de barrios que aún mantienen sus nombres o apellidos como forma de identificación; por ejemplo, Villa Dolores, Villa Tejadas. Para esta fecha la población tenía la tasa de crecimiento más alta del país: $3 \%$.

La siguiente fase de crecimiento demográfico y ampliación del área ocupada se produce en el período 1952 y 1980. Cito, entre otros, dos factores:

* el Estado, para intentar solucionar el déficit cuantitativo de vivienda, conforma Consejos de Vivienda para sectores laborales, los cuales exigen a los distintos gobiernos la compra de predios para encarar planes de construcción;

* las organizaciones sindicales, por ejemplo los Sindicatos de Trabajadores Mineros y Federaciones de Fabriles, por exigencia de sus afiliados organizan formas cooperativas y otras modalidades para intervenir en el mercado de tierras adquiriendo extensiones de tierra para su posterior urbanización. Es necesario reconocer que en algunos casos además de la compra de tierras alcanzaron a financiar la construcción de viviendas. Las razones eran lógicas: prever su jubilación o augurando mejor vida para sus hijos abandonar el campamento minero o la periferia de la fábrica. 


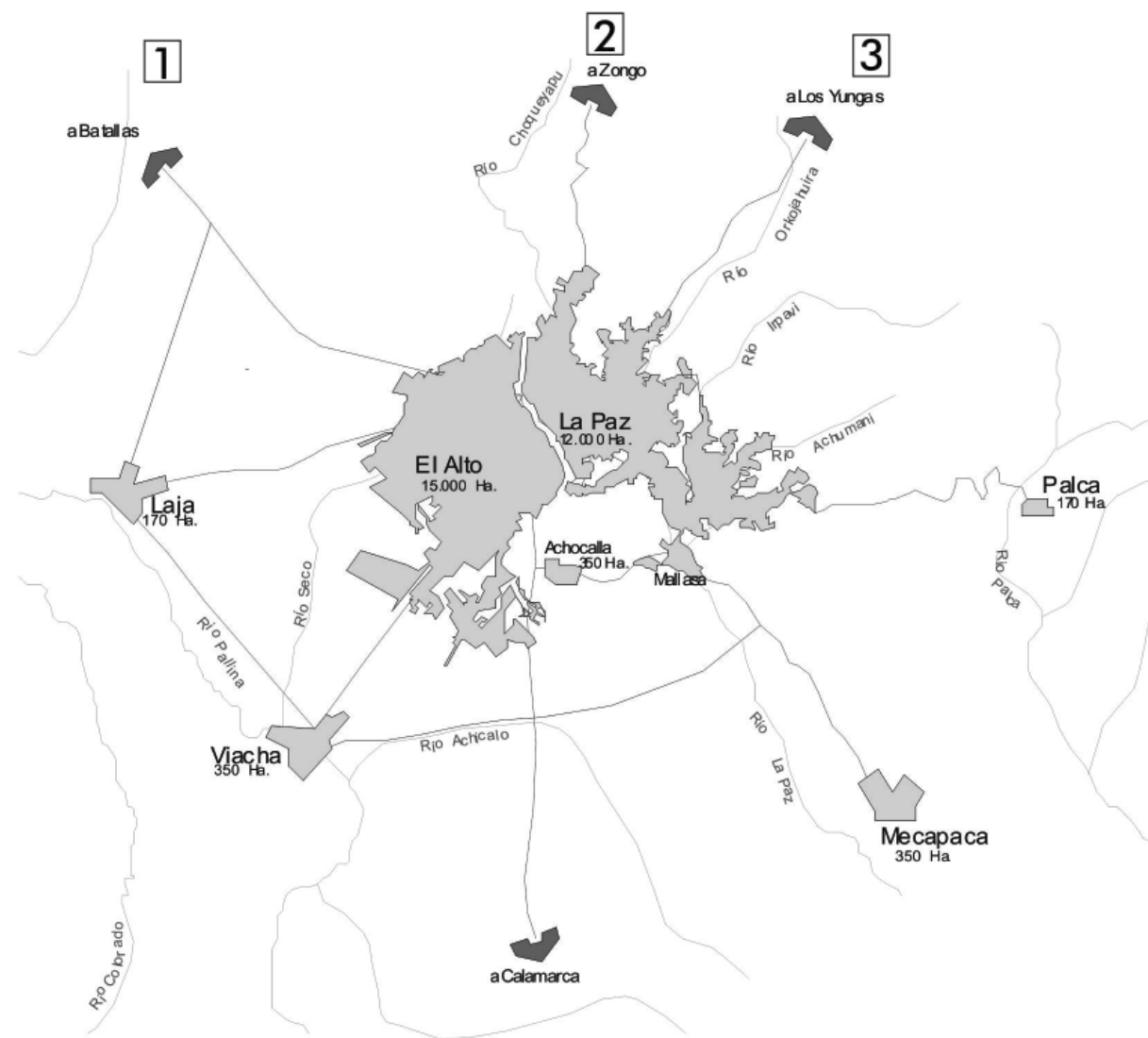

Tendencias históricas de crecimiento de La Paz y El Alto (1 a Batallas, 2 a Zongo, 3 a Yungas, 4 a Calamarca y Oruro, 5 a Viacha (Seminario La Paz Metropolitana 2005) 
Estos dos factores complementan los procesos de migración interurbanos que complementan la ocupación de las laderas de La Paz y la planicie del Alto de La Paz. Surgen los barrios mineros, fabriles y de otros sectores laborales, con la diferencia de que el Alto de La Paz ya era el distrito de La Paz considerado como área de residencia de la población migrante tanto del altiplano periférico al lago Titicaca como de los campamentos mineros y ciudades de menor importancia.

La referencia cronológica continúa en 1985, año que es un hito histórico para La Paz y el país. El 6 de marzo, por la presión social de la población que reside en el entonces Distrito del Alto, se promulga la Ley 728, que convierte al distrito en la capital de la cuarta sección de la provincia Murillo. Esta reivindicación era reclamada por la población porque en ese entonces la sección de provincia era la condición jurídico-legal para constituirse en ciudad, aspiración concretada el 26 de septiembre de 1988 con la promulgación de la Ley 1014. Ambas leyes permitieron a El Alto constituir su propio gobierno municipal y tomar decisiones al margen de la ciudad de La Paz, y se consolidó la separación.

Entre los argumentos esgrimidos por quienes propiciaron la división, cito:

* legítimas reivindicaciones de la población residente que tenía hechos objetivos para exigir autonomía, como la poca aplicación y permanente postergación de acciones de las autoridades para la atención de sus carencias de servicios públicos;

* sensaciones de abandono y discriminación que siente todo migrante.

Tras los argumentos se sucedieron acciones político-partidarias que encontraron en la división la solución coyuntural al reclamo de cuotas de poder en la estructura partidaria, sus dirigentes encontraron en la división la posibilidad de crear en vez de una dos estructuras similares, una para El Alto y otra para La Paz.

La importancia histórica de 1985 se incrementa; el 21 de agosto el gobierno en ejercicio promulga el Decreto Supremo 21060 e inaugura la denominada Nueva Política Económica, que da paso al neoliberalismo en Bolivia e inicia la progresiva desaparición del Estado como protagonista económico, ocasionando un despido masivo de mineros, fabriles y empleados urbanos que protagonizan una masiva migración:

* más de 150.000 personas migraron de Oruro, Potosí y los centros mineros;

* más de 150.000 personas ligadas a la actividad fabril quedaron desempleadas;

* la pobreza rural incrementó la migración interna. 
Las preguntas son obvias:

* la población interna que migra del campo, de los campamentos mineros, ¿adónde se dirige?;

* los desempleados fabriles ¿dónde buscan alternativas de subsistencia?

Las respuestas también son obvias: la calle, el espacio público y la periferia urbana.

Los centros de las ciudades capitales de departamento, principalmente La Paz y Santa Cruz, son transformados, la arquitectura colonial republicana, modernista y "contemporánea" queda detrás del tumulto provocado por la población que circula o tiene en la calle el lugar de su ocupación y subsistencia:

* el grado de concentración de actividades y hacinamiento hacen inútiles las posibilidades de organización del tráfico;

* la población desempleada por el retiro forzoso provocado por el cierre de las empresas estatales "ocupa" las aceras con la venta de mercancías de toda naturaleza y todo precio.

A un mes y cinco días de la promulgación del D. S. 21060, la flamante ciudad de El Alto y se suma a la resistencia popular al modelo neoliberal; desde su periferia y de la de La Paz surgen barrios que producto de la migración y de las condiciones de vida se convierten en emblemas de la resistencia social.

La naciente ciudad de El Alto desarrolla el proceso de resistencia hasta alcanzar un liderazgo social a nivel nacional que progresivamente va sustituyendo el liderazgo de La Paz. Es posible parafrasear que el modelo neoliberal dio origen a lo que le daría una de las estocadas más fuertes. El fundamento está en su condición de nodo atractivo para continuar conquistando a la migración, a la campesina, proveniente principalmente de las provincias de Ingavi, Pacajes, Los Andes, Omasuyos y Manco Kapac del departamento de La Paz. Se suma la migración de los mineros y población vinculada con esta actividad que se radicaba en Llallagua, Catavi y Huanuni y otras localidades de Potosí y Oruro. Esta población conformará barrios que con posterioridad, en febrero y octubre de 2003, serán protagonistas de levantamientos sociales que transformarán la vida política de Bolivia consolidando el único caso de configuración metropolitana en el país motivada por la separación, contraria al fenómeno común de conformación de regiones metropolitanas por la unión de ciudades. 


\section{La región metropolitana boliviana de La Paz-El Alto}

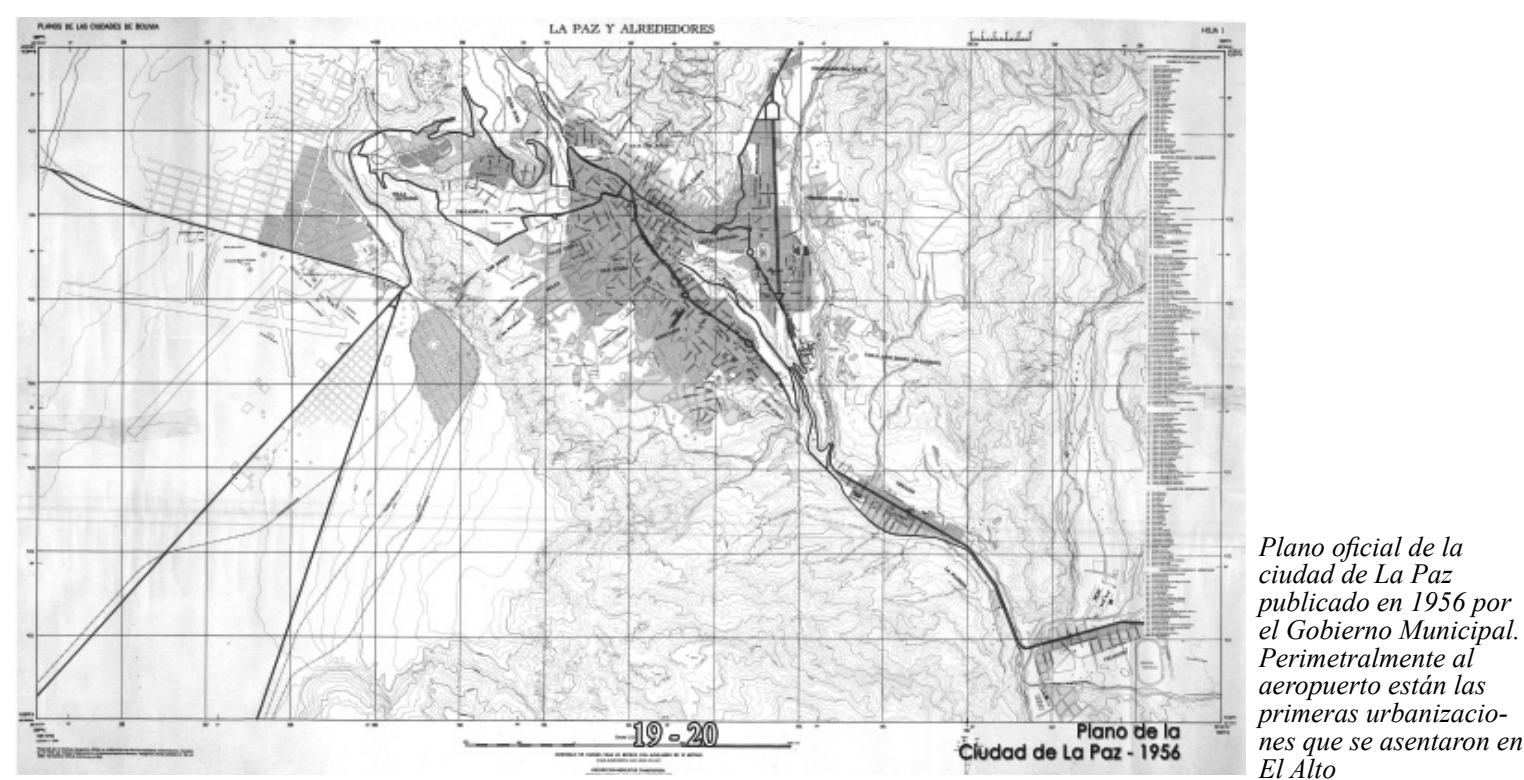

\section{PROBLEMAS DE LA REGIÓN METROPOLITANA}

A los problemas característicos de las metrópolis latinoamericanas la región metropolitana La Paz-El Alto suma uno que condiciona su conformación: la falta de identidad regional.

La identidad regional es el motor que puede impulsar a la región metropolitana tanto a nivel institucional como social; se constituye en la conciencia que cohesiona el territorio.

Frente al proceso "natural" de unión de ciudades para conformar metrópolis en ciudades separadas como La Paz y El Alto, es más difícil conformar una identidad regional. 
La separación está precedida y condicionada por hechos y sensaciones de disputa y enfrentamiento que obligan a pasar de la susceptibilidad al rechazo. La separación condiciona la conducta humana, la sensación de ataque y defensa son permanentes, siempre está latente la agresión.

La separación está motivada por el rechazo y la desconfianza, sensaciones y acciones que determinan que el territorio sea apropiado a partir de la disociación que motivan la fragmentación y la desarticulación territorial, y en tanto no se desarrollen acciones que vayan disminuyendo estas significaciones imaginarias que impiden la materialización de una cultura de complementariedad, subsidiariedad y reciprocidad, atender los problemas de la población será una tarea más difícil.

¿Cuál es el origen de estas sensaciones?

La Paz, al ser una ciudad colonial, tuvo como su razón de ser la discriminación y segregación: "barrio de españoles", "barrio de indios". La constitución de la República no superó este problema estructural; solo sucedieron variaciones formales. Con el transcurso del tiempo el actual municipio de El Alto recibió y recibe denominaciones que suponen un carácter subsidiario y dependiente de La Paz, por ejemplo, "ciudad dormitorio', "ciudad de paso"; suponen conflicto, por ejemplo, "bomba de tiempo", y pretenden crear una identidad propia, al margen de La Paz, por ejemplo, "Ciudad aymara-nueva Tiahuanacu", "ciudad del futuro".

Estas denominaciones exacerban posiciones localistas hasta crear símbolos propios e identidad sobre la base del rechazo al otro, que llevan a acciones y conductas contradictorias. La población convive, se articula y complementa cotidianamente, pero en determinados momentos, ante la aparición de problemas y la incapacidad de encontrar soluciones conjuntas, es más fácil asumir condiciones de víctima y endilgar la responsabilidad de los problemas al otro. La acción equivocada de autoridades y líderes sociales aumenta el rechazo, y surge el enfrentamiento.

Además de la identidad regional se presentan problemas específicos para ser considerados, y debo empezar por los servicios básicos: en el caso del agua, el déficit en la dotación para los cerca de dos millones de habitantes que ocupan la región en las actuales circunstancias tiene muchas dificultades para ser atendido. La visión fragmentada con la que se considera esta carencia ni siquiera permite reconocer que la localización de las fuentes de agua está fuera de los límites administrativos de ambos municipios. 


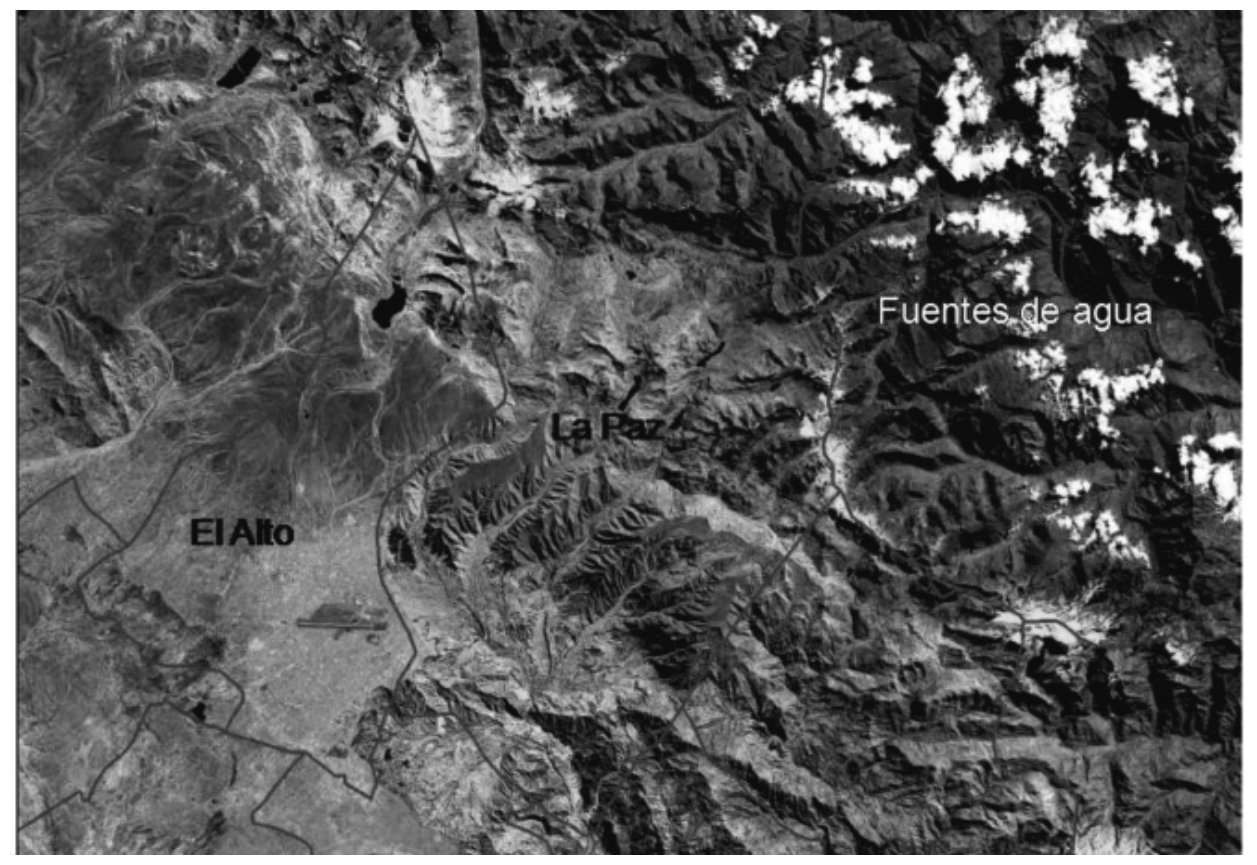

Similar situación se presenta en el caso de las redes de alcantarillado tanto pluvial como sanitario, ya que las acciones que se realizan para cubrir los requerimientos también se caracterizan por su parcialidad, lo que contribuye al deterioro ambiental de municipios aledaños, ya que los residuos producidos son descargados - como en otras ciudades del país y del planeta - directamente al sistema hídrico, con la consiguiente contaminación de zonas productoras de verduras, frutas y hortalizas, que pese a eso mantienen su vocación productiva y continúan suministrando sus productos a La Paz y El Alto. No existe un sistema de recolección y tratamiento de residuos sólidos que permita la satisfacción de la población metropolitana.

La localización de los rellenos sanitarios es otro ejemplo. La generación de residuos se produce en La Paz, y la localización del relleno está en un área cuya jurisdicción
Localización de las fuentes de agua para las ciudades de La Paz y El Alto. Las líneas representan los limites administrativos de ambas ciudades 
administrativa es pretendida por otro municipio; entonces, de tanto en tanto, reivindicaciones locales llevan al bloqueo del camino de acceso y el servicio es interrumpido afectando la salud de toda la población.

Otro problema es la movilidad urbana, atendida por más de cuarenta organizaciones, entre sindicatos y asociaciones de transportistas que regentan las áreas de su cobertura como patrimonio corporativo y muchas veces inexpugnable, lo que inhibe o paraliza la acción municipal. Si bien el costo del servicio es considerado barato, esta condición se relativiza por la calidad que se oferta. Los vehículos son, en su mayoría, adaptados y en franco deterioro, y la organización de las rutas incide en el congestionamiento de determinados sectores de ambas ciudades e influye en el deterioro de la calidad de vida urbana. La Unidad de Sistemas Viales del Gobierno Autónomo Municipal de La Paz ha calculado un aproximado a 1,8 millones viajes/día y un $85 \%$ que se realizan en transporte público. Desde luego que el flujo mayor se realiza entre las ciudades de La Paz y El Alto.

La infraestructura social destinada a salud, educación y los otros equipamientos que deben responder a las necesidades sociales y culturales de la población es la expresión de la desarticulación territorial. La localización de la infraestructura no está en proporción con las necesidades de la gente y no responde a una visión sistémica que garantice una atención adecuada. La infraestructura está localizada en función de las presiones sociales; por ejemplo, la ubicada en La Paz, pese a la distancia, es usada de manera preferente por la población de El Alto, y la que reside en municipios del altiplano paceño prefiere utilizar la infraestructura localizada en El Alto que la que está en sus municipios. Mientras que los flujos poblacionales reconocen la continuidad territorial, la práctica rígida institucional y normativa privilegia la delimitación administrativa impuesta sin razones, que desconoce mecanismos de coordinación y articulación territorial para el beneficio de los habitantes.

Los problemas metropolitanos en el ámbito económico ratifican el carácter sintetizador de las Relaciones Sociales de Producción que tiene el territorio, y en el caso de la región metropolitana La Paz-El Alto la imagen de ambas ciudades expresa las características de una sociedad y un territorio en los cuales las leyes del mercado siguen determinando la economía. Es suficiente transitar por las calles para identificar que la preeminencia del mercado, la presencia de vendedores instalados en el espacio público, las gigantografías que cubren las fachadas de los edificios, el transporte público que modifica rutas y recorridos de acuerdo con la hora, zona y demanda de la gente dominan el paisaje urbano. 
A manera de referencia cito un indicador económico que considero suficiente para respaldar lo escrito. La estructura de la población ocupada por ciudad y sector del mercado de trabajo según sexo para el año 2009 (CEDLA 2009), emergente de la encuesta a 1.638.715 personas de las ciudades de La Paz, Santa Cruz, Cochabamba y El Alto, de las cuales corresponden a La Paz 337.119 y a El Alto 414.672, menciona los siguientes porcentajes:

\begin{tabular}{|l|l|l|l|}
\hline Ciudad & Sector del mercado de trabajo & Hombres (\%) & Mujeres (\%) \\
\hline \multirow{5}{*}{ La Paz } & Estatal & 16.3 & 12.2 \\
\cline { 2 - 4 } & Empresarial & 31.7 & 20.5 \\
\cline { 2 - 4 } & Semiempresarial & 22.8 & 16.5 \\
\cline { 2 - 4 } & Familiar & 29.2 & 46.6 \\
\cline { 2 - 4 } & Servicio Doméstico & --- & 4.4 \\
\cline { 2 - 4 } & Total & 100.00 & 100.00 \\
\hline \multirow{5}{*}{ El Alto } & Estatal & 11.4 & 6.9 \\
\cline { 2 - 4 } & Empresarial & 20.6 & 10.3 \\
\cline { 2 - 4 } & Semiempresarial & 27.7 & 14.9 \\
\cline { 2 - 4 } & Familiar & 40.3 & 65.9 \\
\cline { 2 - 4 } & Servicio Doméstico & --- & 2.1 \\
\cline { 2 - 4 } & Total & 100.00 & 100.00 \\
\hline
\end{tabular}

Sin entrar en detalle de las particularidades que fundamentan por qué y cómo se definen los cinco sectores, inicio la consideración planteando la siguiente hipótesis: los sectores estatal y empresarial, a diferencia del semiempresarial, familiar y de servicio doméstico, cumplen estrictamente las disposiciones legales que garantizan empleo estable y los derechos emergentes como los servicios sociales. Los datos muestran que solo en el caso de los hombres que viven en La Paz la población que hipotéticamente tiene empleo estable supera un tercio del total de la población encuestada. Otro dato, la sumatoria de la población ocupada en los sectores más cercanos a la inseguridad laboral, servicio doméstico, familiar y semiempresarial muestra a la población de El Alto, en especial las mujeres, en situación más precaria que la de La Paz. Considero ambos aspectos suficientes para ratificar las características económicas de las ciudades que concentran población y que por razones estructurales están — por el momento - lejos de garantizar una calidad de vida adecuada a sus habitantes. 


\section{PROCESOS DE TRANSFORMACIÓN PRESENTES EN LAS CIUDADES Y LA RE- GIÓN METROPOLITANA}

La intrínseca dificultad de acercarse en el análisis y la teoría a la velocidad de las transformaciones urbanas y territoriales se incrementa cuando por razones de espacio se deben economizar los textos, y asumo el riesgo de caer en generalizaciones que den una señal inadecuada de los cambios que se van sucediendo de manera permanente.

En la región metropolitana de La Paz-El Alto el contexto socioeconómico, cultural y político actual hace de La Paz una ciudad de servicios públicos y comerciales; su condición de sede de gobierno y sede de Asamblea Legislativa Plurinacional son determinantes. El Alto tiene las mismas características; la diferencia está en la calidad y tipo de servicios y comercio que oferta por las características de la población migrante que la habita. Estas particularidades las hacen complementarias, complementariedad que se manifiesta cotidianamente. Sin embargo, también en la cotidianidad conviven diferencias que aparecen como insalvables. Es posible señalar que las insistencias en privilegiar las diferencias frente a las complementariedades surgen desde posiciones radicales que lindan en el racismo, mostrando a El Alto como la ciudad que reivindica culturas precoloniales sin presencia significativa de culturas mestizas y contemporáneas, y para fundamentar esta convicción muestran a La Paz como la ciudad representante de culturas occidentales y negadora de las precoloniales. Este tipo de reduccionismo no corresponde con la realidad; sin embargo, cobra importancia por su uso mediático y los fines políticos que tienen los partidos que se suman a estas posiciones buscando hegemonizar las relaciones de poder regional.

Es evidente que el proceso histórico de La Paz y El Alto demuestra que la mayoría de la población que vive en El Alto no ha recibido por parte de la sociedad y del Estado oportunidades - por ejemplo, en la formación escolar y universitaria - que le permitan acceder a empleos que requieren una formación previa; entonces para subsistir aprovecha el entorno físico natural y la posición estratégica de la ciudad y se dedica al comercio. Es por eso que su nexo con los municipios denominados rurales no desaparece, y esto hace que El Alto formalmente aparezca como una ciudad homogénea, aunque, desde luego, no lo es, ya que por debajo subyacen actividades productivas que, prescindiendo de la formación escolar y universitaria, dinamizan la economía de la ciudad y además muestran la hibridez de las culturas.

Desde organismos internacionales y nacionales se publicitan estadísticas que muestran los índices de escolaridad aproximarse al ciento por ciento. Desde luego que esto es bueno, 
y las políticas sociales que lograron este avance son positivas; sin embargo, es necesario considerar si la escolaridad o la formación universitaria son condición suficiente para tener empleo estable cuando la sociedad y el Estado no tienen una estructura económica que garantice condiciones para generar empleo relacionado con los niveles de formación. La población de ambas ciudades presenta rasgos comunes relacionados con la culminación de una carrera universitaria. No es exageración reconocer que quienes alcanzan un título académico combinan su ejercicio profesional con la práctica comercial, práctica que no siempre coincide con la profesión alcanzada.

Este contexto es el marco de las transformaciones espaciales que suceden en la región metropolitana de La Paz y El Alto. En estas ciudades, en las que la vivienda tradicionalmente es considerada como espacio especializado para residencia, deja esa especialización y se constituye en espacio que posibilita la subsistencia y reproducción económica de quien la alcanza a construir. No es temerario señalar que en la mente de todos los que concretizan su aspiración de vivienda propia está presente con más fuerza el valor de cambio antes que el valor de uso.

En ambas ciudades y en el interior de sus barrios se producen variaciones morfológicas, pero en esencia la conducta es similar, el criterio que define la magnitud de la transformación es la concentración y congestionamiento de las áreas. Aquellas que se construyen en torno al eje de una vía de interconexión barrial, urbana, intermunicipal, interprovincial o interdepartamental son las que expresan los procesos de transformación; constituyen nodos que son parte de la imagen de la ciudad, modifican la funcionalidad de las viviendas y condicionan su morfología al afán de intercambio.

Los espacios del primer piso se destinan a la compra y venta de mercancías, pueden ser tiendas de barrio, sucursales bancarias, la decisión final estará en función de la concentración de gente. La segunda planta es destinada a provisión de servicios que en algunos casos son especializados, por ejemplo, gastronomía, o combinados, gastronomía y oficinas de servicios personales emergentes del ejercicio profesional; por ejemplo, peluquerías y consultorios médicos. La tercera planta puede destinarse a una unidad habitacional, departamento para alquilar o destinarse a recreación nocturna, discoteca, para finalmente destinar el último nivel a la residencia familiar. En este caso se toma en cuenta la cantidad de hijos que serán los herederos del patrimonio familiar para la subdivisión. Muy poco interesa la fragilidad del suelo o la normativa institucional municipal para el uso del suelo; la velocidad de la intervención privada es siempre mayor que la acción institucional municipal, además de que de esta muchas veces impone modelos organizativos de otras 
realidades, precedidas por una lógica, explícita o no, de que a la ciudad es posible acartonarla y esquematizarla con modelos rígidos y estáticos.

Una calle de El Alto que muestra los usos diferenciados por nivel de la construcción y conforman la morfología urbana. (Foto: José Plaza 2011)

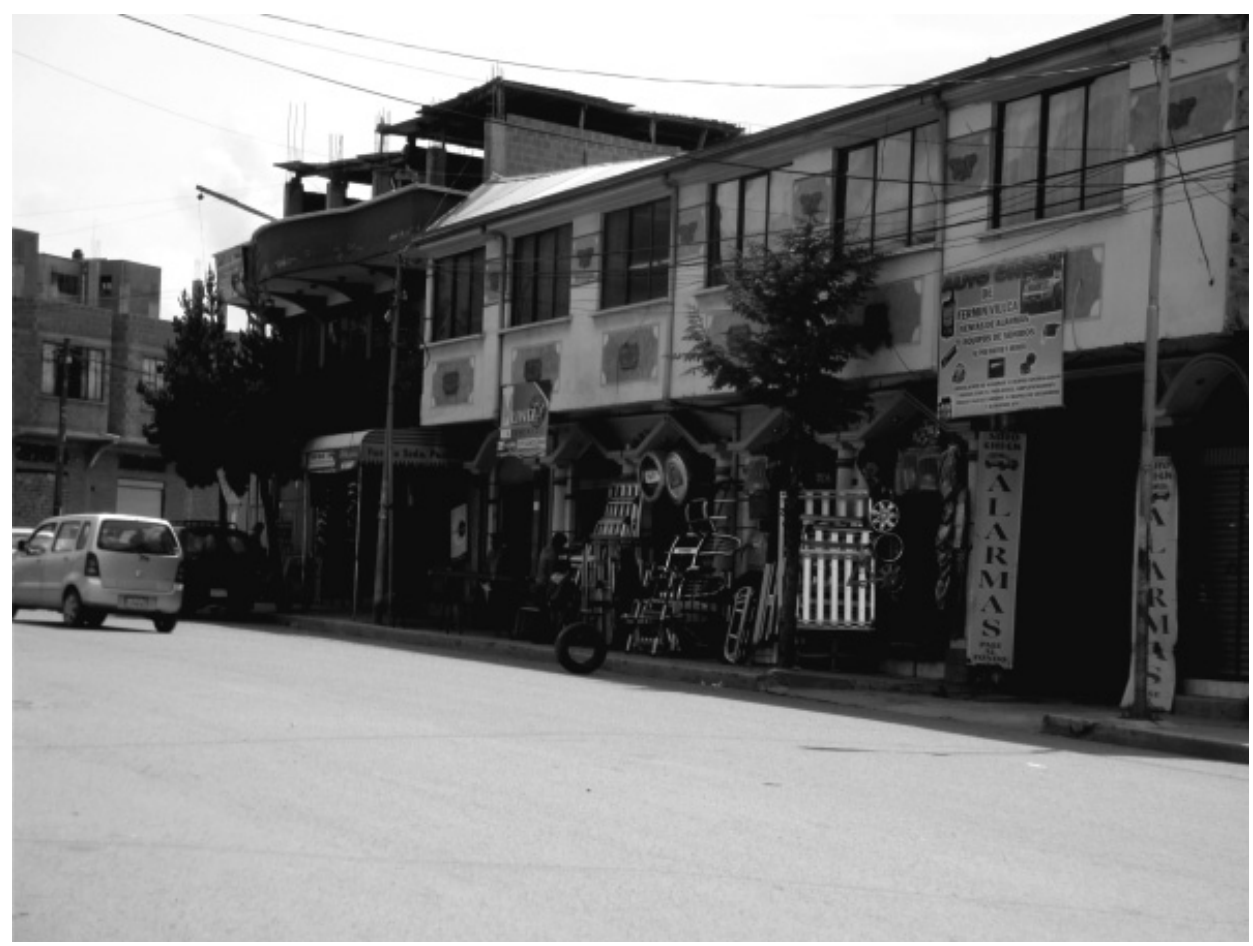

La descripción anterior puede ser entendida como la estrategia de respuesta a las necesidades crecientes de una familia migrante de origen andino y localizada en la ciudad de El Alto; esto no es así. También se presenta en la ciudad de La Paz, inclusive en barrios que hasta hace tres décadas, más o menos, eran considerados exclusivos, en los que la morfología caracterizaba a las viviendas con residencias señoriales unifamiliares localizadas en terrenos de más de 500 metros cuadrados y complementados por jardines que, aprovechando las condiciones naturales de temperatura y clima, sustituyeron las áreas de 
cultivo de alimentos por ray grass y palmeras. En estos barrios y en la última década los propietarios y herederos iniciaron un proceso intenso para sustituir las casas, para construir edificios en altura o transformaron los amplios jardines en áreas para la exposición de vehículos nuevos y seminuevos destinados a la venta, venta de distintas mercancías o también el funcionamiento de locales de diversión nocturna. Ya se presentaron, en barrios de esta característica, tensiones sociales generacionales entre vecinos jóvenes herederos que quieren la demolición, que se enfrentan con los vecinos mayores, quienes quieren la preservación de sus casas y seguir gozando del sol y del paisaje, riquezas naturales que interesan a los jóvenes pero que pretenden disfrutarlas de manera distinta, tal vez en uno de los departamentos en propiedad horizontal que recibirán en forma de pago por la venta de su propiedad o comprando un terreno en la actual periferia para así continuar con la expansión y el crecimiento desordenados de La Paz o migrando a otra ciudad.

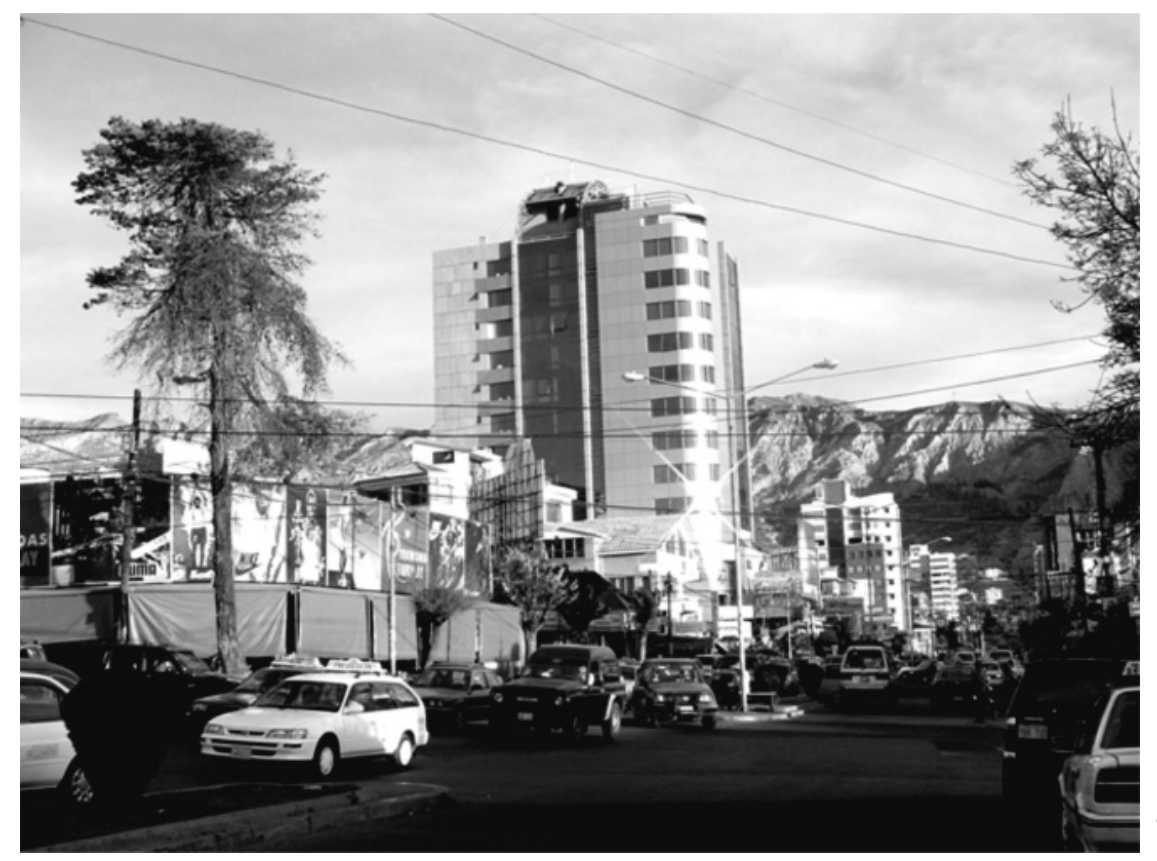

Calle 21 del barrio "residencial" Calacoto, ejemplo contundente de las transformaciones urbanas (Foto: extraida de la red Internet) 
La acción de la población en el proceso de transformación no está sola, es acompañada por la acción institucional de los gobiernos municipales. Uno de los indicadores que sustenta esta afirmación es el manejo presupuestario.

De acuerdo con las normas vigentes, los gobiernos municipales tienen como principales fuentes de financiamiento a las siguientes:

* Recursos propios:

-impuestos a la propiedad de inmuebles y vehículos;

-impuestos a la transferencia de inmuebles y vehículos;

-operación y venta de bienes y servicios;

-tasas, derechos y patentes y sentajes (autorizaciones municipales para actividades económicas de producción, venta o servicios que, por ejemplo, no pagan el impuesto al valor agregado, pese a ser una actividad comercial).

* Recursos provenientes del Tesoro General de la Nación que corresponden a tres fuentes:

-de participación popular (provenientes de impuestos nacionales que se distribuyen de acuerdo con el número de habitantes. La denominación es coincidente con la de una ley sustantiva del neoliberalismo, la Ley 1551 de Participación Popular, que tuvo y tiene un fuerte contenido simbólico y pervive con el actual proceso);

-Impuesto al Valor Agregado;

-Régimen Complementario-IVA;

-Impuesto a las Utilidades de Empresas;

-Impuesto a las Transacciones;

-Impuesto al Consumo Específico;

-Gravamen Aduanero Consolidado;

-Impuesto a las Salidas al Exterior e

-Impuesto a las sucesiones.

-IDH (impuestos provenientes de la venta de hidrocarburos, se distribuyen de acuerdo con el número de habitantes);

-HIPC (sigla en inglés del programa de lucha contra la pobreza, se distribuyen de acuerdo con el número de habitantes).

El gasto (CEDIB, 2011) municipal está concentrado en cuatro rubros:

* infraestructura urbana y rural;

* educación; 


\section{La región metropolitana boliviana de La Paz-El Alto}

* salud y

* saneamiento básico.

De acuerdo con el estudio de referencia se presentan las siguientes particularidades: gran desproporción entre lo destinado a infraestructura urbana/rural y lo destinado a saneamiento básico, servicios de salud y educación.

No es objeto de consideración del presente artículo el detalle cuantitativo de los montos que se destinan al funcionamiento de la institucionalidad municipal; el interés está dirigido

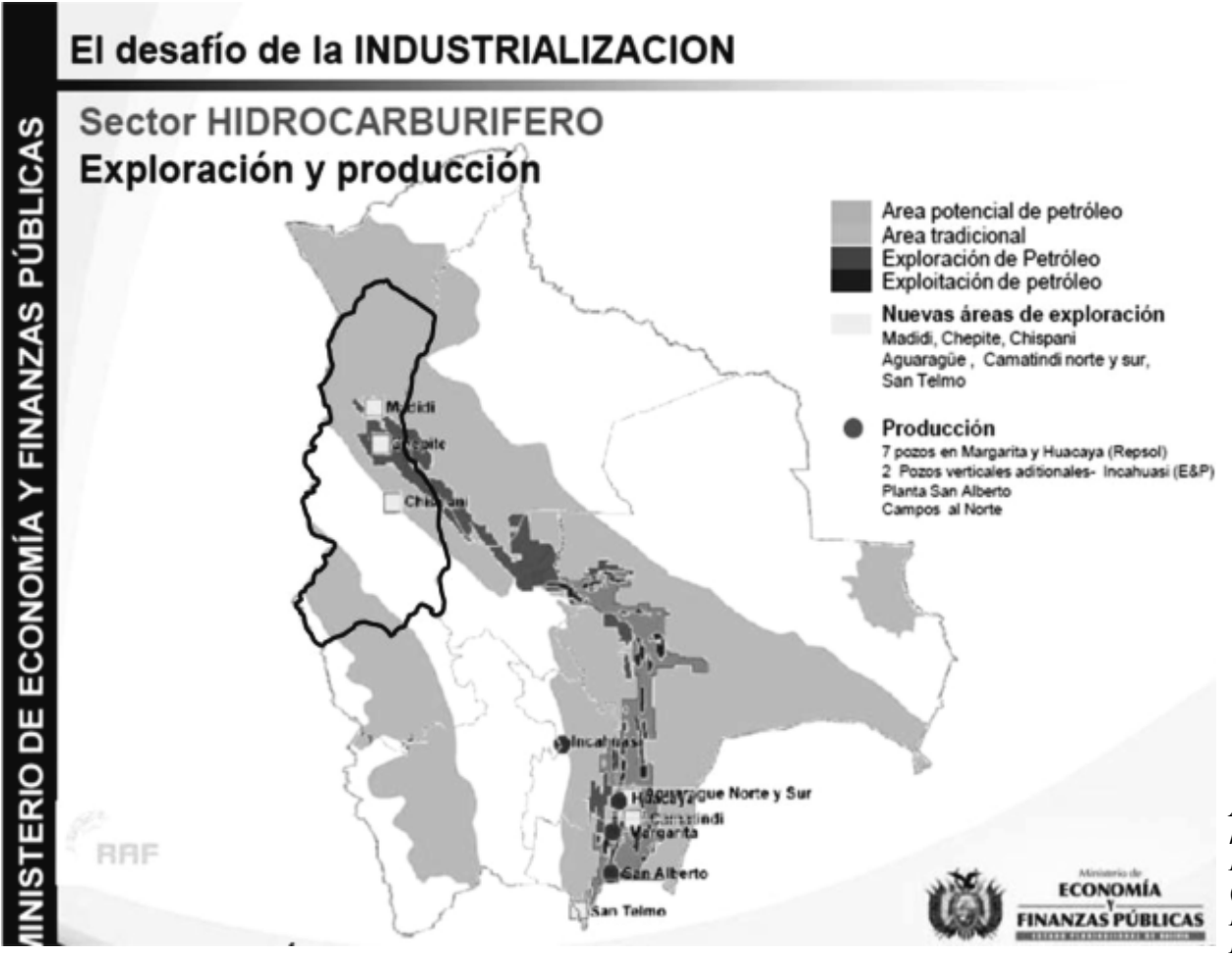

Áreas de exploración hidrocarburifera del Departamento de La Paz (Fuente: Ministerio de (Fuente: Ministerio de
Economia y Finanzas Públicas 2010 


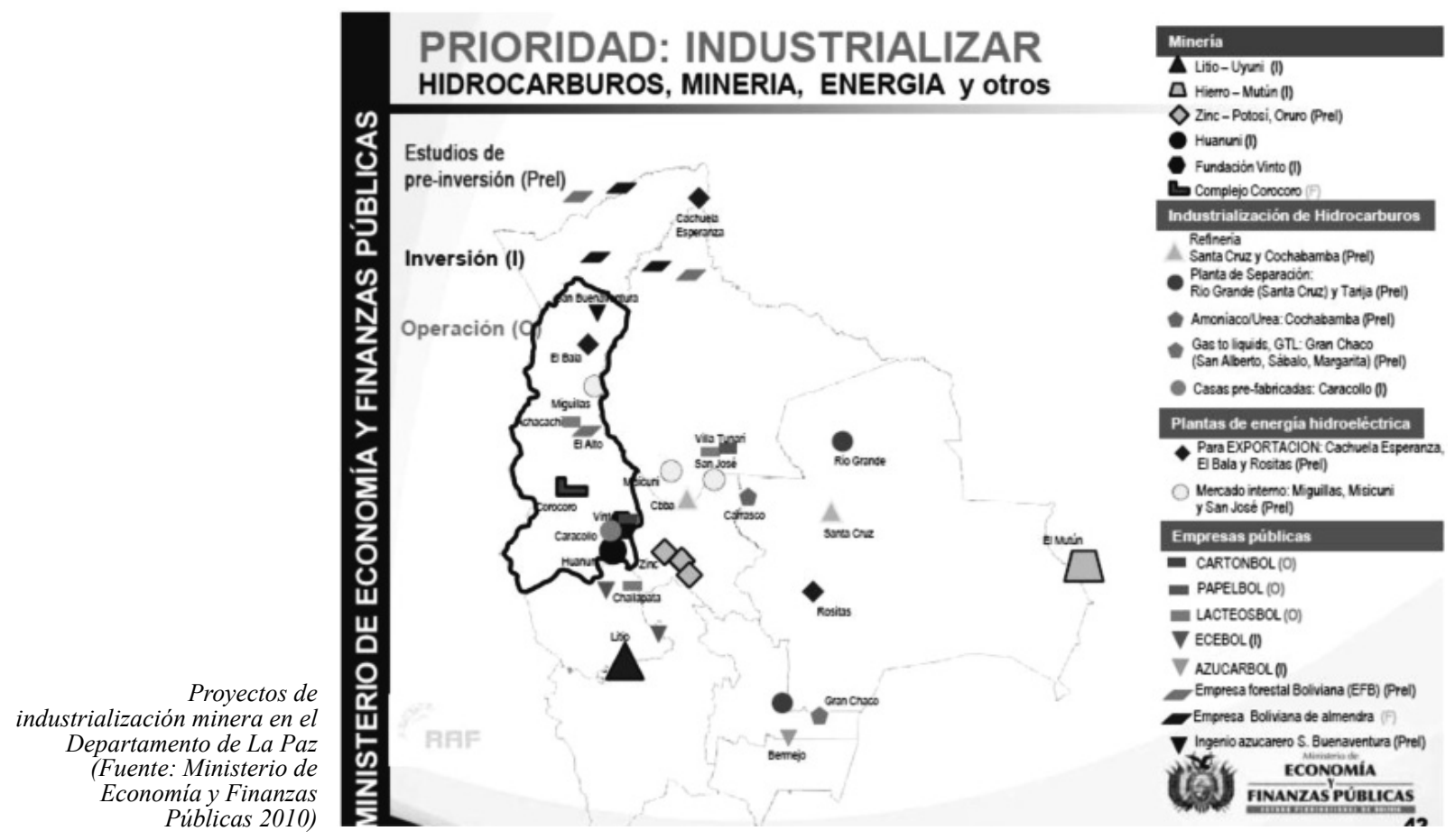

a comprender la lógica con la que se administran los recursos públicos, y por lo anotado se puede señalar que la acción de la institucionalidad municipal es el correlato de la acción individual y la del órgano central del Estado; es decir, la generación de empleos estables no es responsabilidad suya, es del mercado, por eso es que las inversiones fuertes están destinadas a obras de mejoramiento vial e infraestructura urbana. Es que la construcción de aceras y también el asfaltado de vías significan la posibilidad de mejorar las condiciones de uso del espacio público para la compra y venta. Es posible que está afirmación sea entendida como algo despreciable; ante esa situación, solo cabe recordar que la conducta humana no siempre es explicable. 


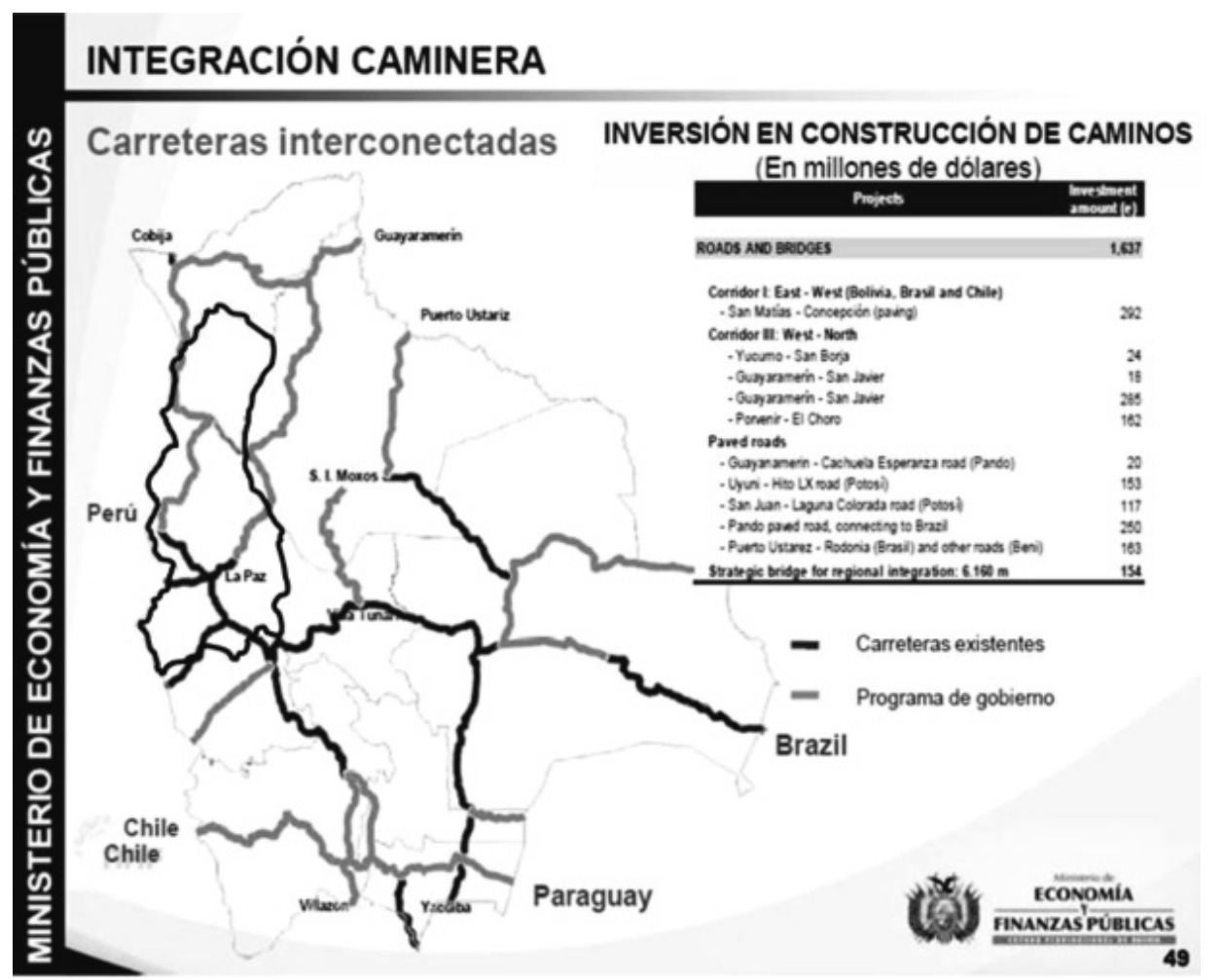

Caminos carreteros que vinculan al Departamento de La Paz (Fuente: Ministerio de Economía y Finanzas Públicas 2010)

\section{ESCENARIOS Y TENDENCIAS}

Considero que es muy limitado intentar avizorar escenarios futuros y tendencias sin reflexionar sobre la condición natural que acompaña a la ubicación de la Región Metropolitana La Paz El Alto, ya que le otorga un carácter estratégico. Está localizada como un nodo de vinculación entre el Amazonas y el Océano Pacífico, condición que extiende su influencia a las ciudades fronterizas del sur del Perú y del norte de Chile. 


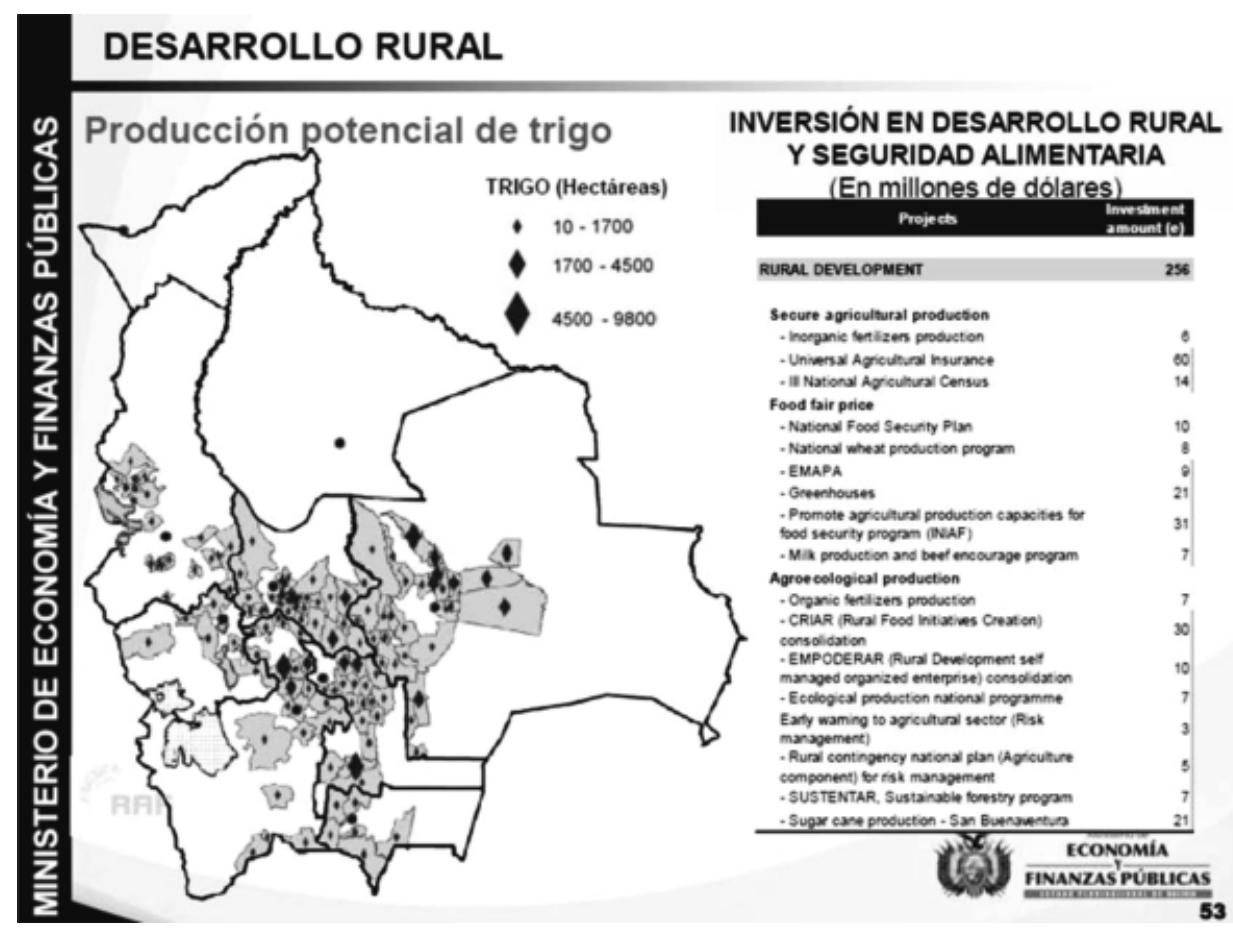

Los proyectos de inversión para el quinquenio 2010-2015 anunciados por el gobierno del Estado, tanto en el sector hidrocarburífero, minero, industrial, vinculación caminera, e inclusive el potencial triguero conforman un escenario favorable.

Lo favorable del escenario debe ser complementado con los aspectos que se presentan como adversos. Cito entre ellos:

* disminución de la seguridad alimentaria;

* desastres naturales, ocasionados por los humanos, más frecuentes y de mayor intensidad; por ejemplo, el incremento de incendios forestales, inundaciones complementadas con sequías que entre otras consecuencias significan el aumento de enfermedades. 


\section{La región metropolitana boliviana de La Paz-El Alto}

Algo que en algún momento se creía irracional ya sucede: en El Alto, a más de 3600 msnm, se han detectado mosquitos que eran típicos de áreas tropicales;

* pérdida del paisaje natural (figura 10);

* Disminución de las reservas acuíferas. La Paz y El Alto son especialmente vulnerables; la futura desaparición de glaciares condiciona el agua potable que se necesita para el consumo humano, además de que miles de campesinos dependen del deshielo para el riego de sus cultivos.
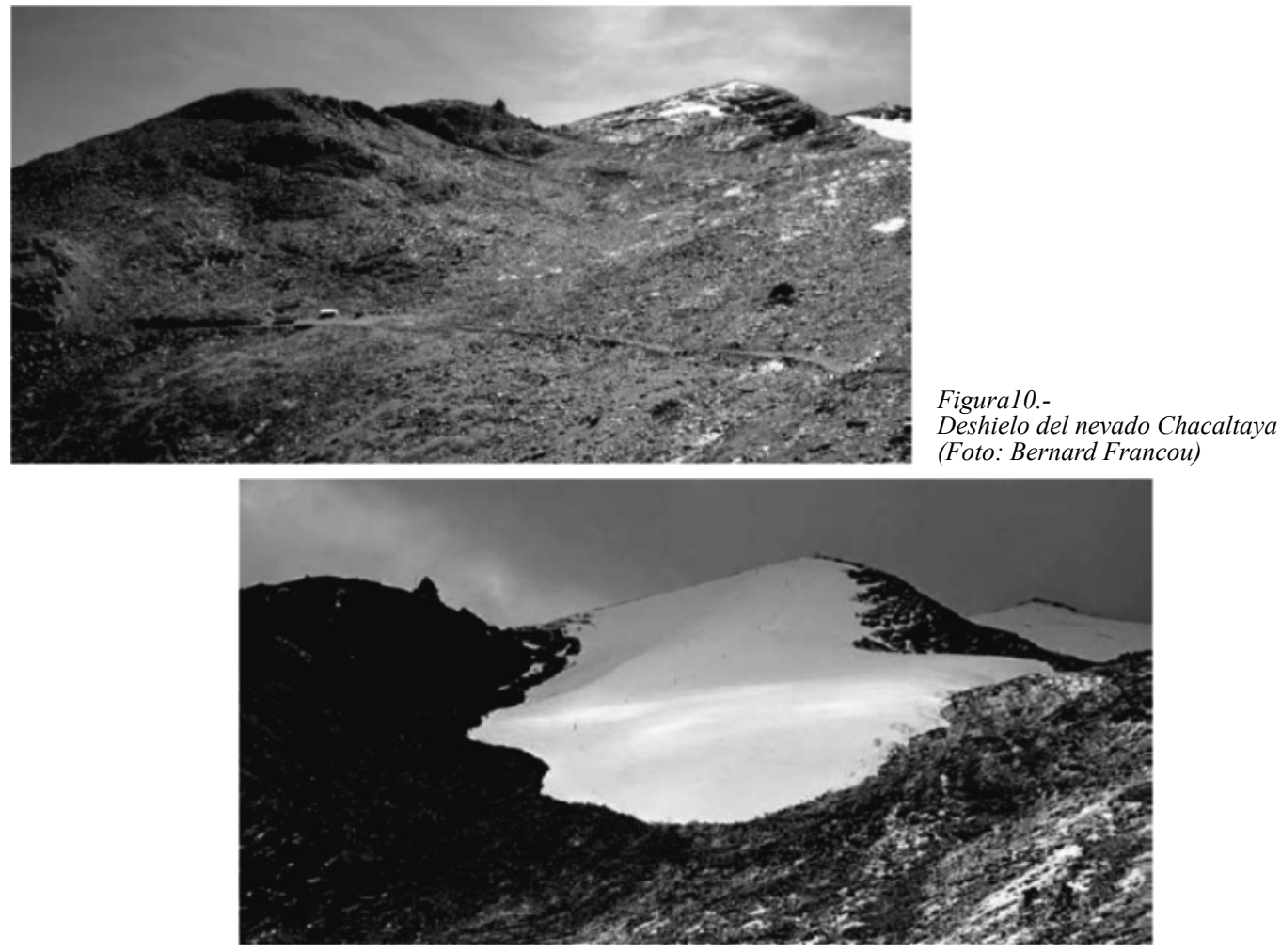
La interpretación y proporción que se encuentren como consecuencia de la evaluación de los aspectos positivos y negativos descritos tiene que estar precedida por acciones que empiecen a configurar una conciencia social regional, y el Estado en su conjunto es el responsable, ya que la organización territorial sustentada en el reconocimiento de la Región Metropolitana La Paz-El Alto involucra una continuidad territorial administrada por otros municipios además de los mencionados. Los gobiernos municipales deben cambiar sus formas de acción: la confrontación debe ser sustituida por la complementariedad, la solidaridad y la reciprocidad, ya que los problemas merecen la atención integral. Este accionar influirá en la conformación de la conciencia social requerida, aspecto fácil de escribir pero difícil de materializar, y por eso es una responsabilidad del Estado en todos sus niveles.

En complementación con esta prioridad se debe ir creando una institucionalidad regional que además de estar referida en la Constitución Política del Estado incluya niveles de gestión, planificación y ejecución de proyectos que preserven el medio ambiente, resuelvan las carencias de servicios básicos, dinamicen la economía y generen empleos, creen una institucional compartida a partir de reconocer las particularidades de las actuales y futuras formas de apropiación territorial. Estas referencias genéricas deben ser concretadas con la identificación de iniciativas que identifiquen proyectos desde la gestión de riesgos que disminuyan la fragilidad de la región, hasta la construcción de parques tecnológicos, que sean concretados.

\section{BIBLIOGRAFÍA}

BANCO MUNDIAL http://econ.worldbank.org (2012).

CEDLA (Centro de Estudios para el Desarrollo Laboral y agrario) http://www.cedla. org. Encuesta Urbana de Empleo 2009.

CEDIB (Centro de Documentación e Información de Bolivia) (2011) Presupuestos Urbanos, De la ritualidad participativa a la imposición del concreto. Un estudio de la inversión municipal en las cuatro ciudades del Eje de Bolivia.

CONSTITUCIÓN POLÍTICA DEL ESTADO PLURINACIONAL DE BOLIVIA (2009).

GOBIERNO MUNICIPAL DE LA PAZ (2006) Atlas del Municipio de La Paz. POPULATION REFERENCE BUREAU http://www.prb.org (2012). 